\title{
Placenta Accreta Overlying a Caesarean Section Scar: A 10-Year Experience in a Tertiary-Care Centre in Portugal
}

\author{
Placenta Acreta Sobre Cicatriz de Cesariana: Experiência \\ de 10 Anos de um Centro Terciário em Portugal
}

\author{
Margarida CAL ${ }^{1}$, Carla NUNES ${ }^{2}$, Nuno CLODE¹, Diogo AYRES-DE-CAMPOS ${ }^{1}$ \\ Acta Med Port 2021 Apr;34(4):266-271 - https://doi.org/10.20344/amp.14001
}

\section{ABSTRACT}

Introduction: Placenta accreta spectrum disorders are among the leading causes of maternal morbidity and mortality and their prevalence is likely to increase in the future. The risk of placenta accreta spectrum disorders is highest in cases of placenta previa overlying a previous cesarean section scar. Few studies have evaluated placenta accreta spectrum disorders in Portugal. The aim of this study was to review the cases of placenta accreta spectrum overlying a cesarean section scar managed in a Portuguese tertiary center over the last decade.

Material and Methods: Retrospective, cross-sectional study, with data collected from hospital databases. Only cases with histopathological confirmation of placenta accreta spectrum were included.

Results: During the study period, 15 cases of placenta accreta spectrum overlying a cesarean section scar were diagnosed (prevalence 0.6/1000). All cases were diagnosed antenatally. A transverse cesarean section was present in all cases; 13 were managed by a scheduled multidisciplinary approach, while two required emergent management. Total or subtotal hysterectomy was performed in 12 cases. There were no cases of maternal or neonatal death. Histopathological evaluation confirmed nine cases of placenta accreta, three cases of placenta increta and three cases of placenta percreta.

Discussion: Early antenatal diagnosis is important for a programmed multidisciplinary management of these cases, which may reduce potential morbidity and mortality and ensure better obstetric outcomes.

Conclusion: This case series of placenta accreta spectrum overlying a cesarean section scar reports the reality of a tertiary-care perinatal center in Portugal, in which no maternal or neonatal mortality due to placenta accreta spectrum was registered over the last decade; this may be attributed to prenatal diagnosis and a coordinated multidisciplinary team approach.

Keywords: Placenta Diseases; Placenta Accreta; Portugal

\section{RESUMO}

Introdução: O acretismo placentário está entre as principais causas de morbilidade e mortalidade materna, sendo provável que a sua prevalência venha a aumentar. O risco é máximo em casos de placenta prévia sobre cicatriz de cesariana. Existem poucos estudos sobre esta realidade em Portugal. O objetivo deste estudo foi rever os casos de acretismo placentário sobre cicatriz de cesariana prévia, ocorridos ao longo da última década num centro terciário português.

Material e Métodos: Estudo retrospetivo, transversal, com dados recolhidos de bases de dados hospitalares; foram incluídos apenas casos com confirmação histopatológica de acretismo placentário.

Resultados: Foram diagnosticados 15 casos durante o período do estudo (prevalência 0,6 / 1000). Todos os casos foram diagnosticados durante a gravidez. Em todos os casos foi realizada cesariana; 13 foram agendadas com base numa abordagem multidisciplinar, e duas foram emergentes. Em 12 casos foi realizada histerectomia total ou subtotal. Não se registaram casos de mortalidade materna ou neonatal. O estudo histopatológico confirmou nove casos de placenta acreta, três de placenta increta e três de placenta percreta. Discussão: O diagnóstico pré-natal precoce é fundamental para um planeamento multidisciplinar que permita reduzir a potencial morbilidade e mortalidade e garantir melhores desfechos obstétricos.

Conclusão: Esta série de casos de acretismo placentário sobre cicatriz de cesariana relata a realidade de um centro de assistência perinatal terciário em Portugal, no qual não se registou mortalidade materna ou neonatal ao longo da última década; esta situação é atribuível ao diagnóstico pré-natal eficiente e à abordagem coordenada por uma equipa multidisciplinar.

Palavras-chave: Doenças da Placenta; Placenta Accreta; Portugal

\section{INTRODUCTION}

First described eighty years ago, the term placenta accreta was defined as a clinical-pathological condition in which the placenta fails to separate partially or totally from the uterine wall. ${ }^{1,2}$ It is now generally accepted that placenta accreta results from a defect in the endometrium-myometrial interface, typically at the site of a previous hysterotomy, which leads to a failure of normal decidualization and deep infiltration of placental villous tissue in the exposed and scarred myometrium upon trophoblastic invasion. ${ }^{3}$
The International Federation of Gynecology and Obstetrics (FIGO) published new consensus guidelines proposing a new standardized terminology, with adoption of the term 'placenta accreta spectrum' (PAS) disorders to describe different pathological forms of placentation, which covers all possible combination of depths and lateral extension of villous invasiveness. ${ }^{1,2}$ Recently published FIGO guidelines proposed a new classification of placenta accreta spectrum disorders. ${ }^{1}$ Depending on the depth of trophoblast

1. Departamento de Obstetrícia, Ginecologia e Medicina da Reprodução. Hospital de Santa Maria. Centro Hospitalar Universitário Lisboa Norte. Lisboa. Portugal.

2. Serviço de Ginecologia e Obstetrícia. Hospital de Vila Franca de Xira. Vila Franca de Xira. Portugal.

$\triangle$ Autor correspondente: Margarida Cal. margarida.cal@.gmail.com

Recebido: 27 de abril de 2020 - Aceite: 01 de julho de 2020 - Online issue published: 01 de abril de 2021

Copyright $\odot$ Ordem dos Médicos 2021 
invasion into the myometrium, different subtypes can be distinguished. Grade 1: abnormally adherent placenta (placenta adherenta or creta) refers to cases of extended areas of absent decidua between villous tissue and myometrium with placental villi attached directly to the superficial myometrium. Grade 2: abnormally invasive placenta (increta), refers to cases with placental villi within the muscular fibers and sometimes in the lumen of the deep uterine vasculature (radial or arcuate arteries). Grade 3: abnormally invasive placenta (percreta), subdivides into three categories: grade $3 a)$ limited to the uterine serosa, grade $3 b$ ) with urinary bladder invasion and grade $3 \mathrm{c}$ ) with invasion of other pelvic tissue/organs. ${ }^{6}$ More invasive degrees of placentation probably result from a more extensive scarring. ${ }^{7}$

PAS disorders are among the leading causes of maternal morbidity and mortality, and may be associated with massive obstetric hemorrhage, which leads to secondary complications including coagulopathy, disseminated intravascular coagulation (DIC), hemorrhagic shock, multiple organ dysfunction syndrome (MODS), need for postpartum hysterectomy, admission to Intensive Care unit (ICU) and death. ${ }^{3,8,9}$ Over the past decades, cesarean section (CS) rates have risen steadily all over the world and this was mirrored by a ten-fold increase in the incidence of PAS. ${ }^{10}$ More than $90 \%$ of women presenting with PAS had at least one prior CS. ${ }^{5,10}$ Prior cesarean delivery is the main risk factor for PAS and this risk is increased with higher numbers of previous CS; the second major risk factor for PAS is placenta previa (placenta that partially or completely covers the cervical os), and the overall risk is highest when both factors are present and placenta previa overlays a prior CS scar. ${ }^{11}$

PAS is currently the main reason for post-cesarean and peripartum hysterectomy, accounting for approximately a third of all cases. ${ }^{12,13}$ It is also an important cause of maternal morbidity, with mortality rates reaching $6 \%-7 \%$ in some series. ${ }^{14}$

There are few studies demonstrating the reality of placenta accreta spectrum disorders in Portugal, although these are probably underdiagnosed antenatally. The objective of this study was to examine the cases of PAS overlying a previous cesarean scar that occurred in our institution over the last 10 years, to describe the characteristics of these women, as well as the diagnosis and management of this condition and both maternal and perinatal outcomes.

\section{MATERIAL AND METHODS}

A retrospective study was carried out, including only cases of PAS overlying a cesarean scar diagnosed at our institution, a tertiary perinatal care center, between 2009 and 2018. Cases were identified using cross-reference from different databases (Astraia ${ }^{\circledR}$, Sectra ${ }^{\circledR}$, ICD-9 coding), with combinations of keywords ('placenta accreta', 'placenta creta', 'placenta increta', 'placenta percreta', 'placenta previa', 'low-lying placenta' and 'postpartum hemorrhage'). All cases with histopathological confirmation of PAS, either in the placenta or in the hysterectomy specimen, were included in the study and each case was classified as placenta accreta, increta or percreta, depending on the depth of myometrial invasion according to the conclusion of the pathology report. Medical records of all eligible women and newborns were analyzed and data was extracted and entered into a web-based data system. Extracted data included: demographic characteristics; details of obstetric history; risk factors for PAS (placenta previa, prior CS and its number, previous uterine surgeries or previous PAS); gestational age at the time of diagnosis; reasons for hospitalization and gestational age at delivery. Furthermore, data were collected to ascertain the agreement rate between the ultrasound (US) or magnetic resonance imaging (MRI) diagnosis versus the final histopathological diagnosis concerning the grade of accretism. All information about intrapartum and postpartum events, including previous placement of ureteral stents and/or placement of intra-arterial balloons, operative and hospitalization times, and maternal and neonatal outcomes (until hospital discharge) were also collected. Descriptive analyses were used to report the frequency of adverse outcomes. Maternal outcomes included: ICU admission, need for transfusional support, including massive transfusion (10 or more units of red cells), ${ }^{14}$ coagulopathy, shock, MODS, iatrogenic injury of other organs or need for reoperation within seven days. Neonatal outcomes recorded included gestational age at delivery, weight at birth, Apgar score and need for hospitalization in neonatal ICU.

Data was extracted from an anonymous retrospective database; under these circumstances, at the time of data collection, it was not required to request any specific approval by the ethics committee.

\section{RESULTS}

Between 2009 and 2018 we documented 15 cases of placenta accreta overlying a caesarean section scar, from a total of 23707 births - a prevalence of 0.6 cases per 1000 deliveries, over the 10 -year study period. We excluded a case of anencephaly associated with placenta increta diagnosed at 21 weeks of gestation from this series (as an outlier) in which surgery (hysterectomy with bilateral salpingectomy) was performed at 24 weeks of gestation.

The mean maternal age was 36.8 years [ 27 - 42 years; interquartile range (IQR) 34.5 - 40.5] and approximately three quarters of women diagnosed with PAS were older than 35 years. Regarding obstetric history, there was a median parity of two (IQR 1 - 2). At least one previous cesarean section had been performed in all cases, with its number ranging from one to three. One woman with a previous CS had a history of placenta accreta in the previous pregnancy. All cases presented with placenta previa (13 complete and two partial placenta previa cases). As for other risk factors, there were three cases with history of previous uterine curettage and one case of previous hysteroscopy. No cases of uterine surgeries were registered. Other risk factors as well as basic characteristics of the population are summarized in Table 1.

All pregnancies had a thorough surveillance: there were 
Table 1 - Characteristics of patients with PAS on caesarian scar $(\mathrm{n}=15)$

\begin{tabular}{lc}
\hline Characteristic & $\mathbf{n}(\%)$ \\
\hline Age, years & $2(13.3)$ \\
$<30$ & $2(13.3)$ \\
$30-34$ & $11(73.3)$ \\
$\geq 35$ & \\
Number of prior pregnancies ( $\geq 20$ weeks) & $4(26.7)$ \\
1 & $5(33.3)$ \\
2 & $6(40.0)$ \\
$3+$ & \\
Number of prior cesarean deliveries & $7(46.7)$ \\
1 & $7(46.7)$ \\
2 & $1(6.7)$ \\
3 & $24(22-31)$ \\
Gestational age at diagnosis (weeks)* & $36(34-36.5)$ \\
Gestational age at delivery (weeks)* & \\
\hline${ }^{*}$ median (interquartile range)
\end{tabular}

two cases of hematological conditions diagnosed during the current pregnancy (one case of anemia and one of thrombocytopenia) and three cases of gestational diabetes. All were singleton pregnancies. Assessment of fetal conditions allowed the identification of one case of complex cardiac malformation, one case of interventricular communication and one case of a small for gestational age fetus.

All PAS cases were diagnosed antenatally by ultrasound, on average at 26 weeks of gestation [ $\Delta: 20-36$, IQR 22 - 31]. Regarding evaluation of placental invasion by US versus MRI, diagnosis of placenta accreta was made in three versus eight cases; increta in three versus one case and percreta in nine versus six cases. Bladder invasion was diagnosed by ultrasound in only one case and confirmed by MRI. Delivery occurred on average at 35 weeks of gestation [ $\Delta: 28$ - 38, IQR 34 - 36.5]; there was only one case of placenta accreta diagnosed at 36 weeks of gestation, whose CS was performed at 38 weeks.

Due to prenatal diagnosis, hospitalization and cesarean delivery were scheduled in all cases; however, six women were admitted ahead of schedule due to vaginal bleeding, and in two cases an emergent CS was performed due to severe hemorrhage. As for the other 13 scheduled non-emergent CS cases, there was a multidisciplinary approach: ureteral catheterization was performed in 10 cases and an intra-arterial balloon was placed in the internal iliac arteries in four cases.

A total hysterectomy was performed in nine cases, subtotal hysterectomy in three cases and partial myometrial resection in the remaining three cases. There were two cases of bladder invasion, but only one had been diagnosed antenatally. In these cases, a cystotomy was performed with removal of the affected area, followed by a cystorrhaphy. There was one case of iatrogenic bladder injury during an emergent procedure, also solved with cystorrhaphy. The mean operative time was two hours and 20 minutes
( $\Delta: 1$ hour 10 minutes -3 hours 30 minutes).

Maternal and neonatal outcomes are described in Table 2. Most frequent complications were hemorrhagic shock requiring massive transfusion, disseminated intravascular coagulation and anemia. Transfusional support was required in 13 cases, with a median of two packed red blood cell units $(\Delta: 1-12), 2 \mathrm{~g}$ fibrinogen $(\Delta: 0-4)$ but no platelet $(\Delta: 0-3)$ or fresh frozen plasma units $(\Delta: 0-10)$. Seven women were admitted to the ICU, with a median of five days after surgery until discharge. No cases of maternal death were recorded, neither of multiple organ failure or need for reoperation. The average neonate birthweight was 2502 $\mathrm{g}$; there were three cases of Apgar score under seven at five minutes of life and none at 10 minutes of life. Eleven newborns were transferred to an intermediate neonatal intensive care unit, mostly due to prematurity associated complications; one case of respiratory depression and another of suspected streptococcal infection were registered. Two cases with cardiac malformations were transferred to pediatric surgery units. There were no cases of neonatal death. The pathology report with histopathological study of the placentas confirmed nine cases of placenta accreta, three cases of placenta increta and three cases of placenta percreta. The ultrasound examination correctly diagnosed the grade of accretism in a third of cases $(n=5)$, and this percentage increased with MRI to $60 \%(n=9)$. Ultrasound and MRI evaluations matched in 10 cases, but only five of those were correctly diagnosed according to the histopathological conclusion.

\section{DISCUSSION}

This study presents a case series of PAS overlying a cesarean section scar diagnosed and managed at a tertiary center, in which it was possible to conduct a multidisciplinary preoperative management, resulting in the absence of maternal or neonatal mortality. Institutional protocols were followed, and cases were managed by a dedicated team. These results reinforce that women with antepartum diagnosis of PAS disorders, with or without placenta

Table 2 - Maternal and neonatal outcomes $(n=15)$

\begin{tabular}{lc}
\hline Maternal outcomes & $\mathbf{n}(\%)$ \\
\hline ICU admission & $7(46.7)$ \\
Blood product transfused & $13(86.7)$ \\
Massive blood transfusion & $2(13.3)$ \\
Lowest postpartum hemoglobin $(\mathrm{g} / \mathrm{dL})^{*}$ & $6.9(6.5-8.85)$ \\
Hemorrhagic shock & $4(26.7)$ \\
Disseminated intravascular coagulation & $4(26.7)$ \\
\hline Neonatal outcomes & $\mathbf{n}(\%)$ \\
\hline Gestational age at delivery (weeks) & $36(34-36.5)$ \\
Neonatal birthweight (g)* & $2720(2363-2755)$ \\
Neonatal ICU admission & $11(73.3)$ \\
Apgar Index < 7 at 5 minutes of life & $3(20.0)$ \\
Apgar Index < 7 at 10 minutes of life & $0(0)$ \\
\hline * median (interquartile range) &
\end{tabular}


previa, should be referred and have their delivery scheduled in tertiary centers - centers of excellence - with a dedicated multidisciplinary team and care plan, thus contributing to improved outcomes and reduction of complications. ${ }^{15-19} \mathrm{Al}-$ though no maternal mortality was registered, we still listed significant maternal morbidity. Similar results were reported by another tertiary center in Portugal regarding PAS cases; in this analysis, all cases of PAS were included, but only three cases were associated with a low-lying placenta in women with previous CS. ${ }^{20}$

Despite the knowledge that surgical risks increase with the depth of placental invasion, causing more severe hemorrhage, these results emphasize the need for PAS cases to be managed in specialized centers, with experienced surgeons and a multidisciplinary team. ${ }^{21,22}$ Choosing the best care plan for women with PAS disorders should include the discussion of each case by a multidisciplinary team in dedicated centers, with capacity to perform complex pelvic surgery, logistic support for access to blood products and intensive care facilities (both adult and neonatal). However, there is still a need for a standardized approach regarding diagnosis and management of PAS disorders. Recent studies found a considerable variation in global PAS practices regarding both Obstetricians and Maternal-Fetal Medicine specialists. $^{23,24}$

FIGO guidelines describe different approaches regarding conservative and non-conservative management of PAS. In terms of conservative management, different techniques have been described, such as: (1) leaving the placenta in situ approach, consisting of leaving the placenta in situ and waiting for its complete spontaneous resorption; (2) one-step conservative surgery (partial myometrial resection followed by immediate uterine reconstruction and bladder reinforcement); and (3) the triple-P procedure (suturing around the accreta area after resection, reconstituting the uterine defect). ${ }^{25}$ Leaving the placenta in situ approach might be an option for women who desire to preserve their fertility and agree to have a close follow-up in centers with ultrasound expertise, although they should be informed about the high risk of recurrence of PAS disorders (approximately $30 \%$ ), and the fact that there is no consensus regarding its management due to insufficient data. ${ }^{26}$

Alternative conservative surgical procedures, including the one-step conservative surgery and the triple-P procedure, might be applied in selected cases where fertilitypreservation is desired. This requires a multidisciplinary team with surgical expertise and full capacity to manage possible complications.

Adjuvant techniques, such as preventive surgical or radiological uterine devascularization, include uterine surgical devascularization, bilateral uterine or hypogastric artery surgical ligation, iliac artery embolization, or balloon occlusion. There is limited evidence supporting the use of these adjuvant techniques because of their high risk of complications. Routine prophylactic placement of balloon catheters in the iliac arteries is nowadays controversial; larger studies are needed to validate the safety and effectiveness of this technique before it can be widely recommended. ${ }^{25,27}$

Preoperative placement of ureteric stents for managing PAS cases is recommended since it is associated with a five-fold risk reduction of urinary tract injuries. During ureteric stent placement, cystoscopy can also help to assess for bladder invasion in cases of placenta percreta.

In terms of non-conservative management, FIGO guidelines state that total hysterectomy with placenta in situ is preferred over subtotal hysterectomy in cases of placenta previa increta or percreta. However, in the case of placenta percreta with extensive pelvic invasion, a delayed hysterectomy with placenta in situ may be considered. ${ }^{19}$

In this series of PAS with placenta previa, three cases were managed through a conservative approach, with partial myometrial resection, while peripartum hysterectomy (nine total and three subtotal) was performed in most cases. There were no records of the estimated blood loss with each of these approaches.

It is estimated that PAS disorders remain undiagnosed prenatally in half to two-thirds of cases. ${ }^{16,28}$ In a recent review from a Portuguese tertiary center, less than $10 \%$ of cases were diagnosed antenatally. ${ }^{20}$ Recognition of women at risk of PAS disorders is crucial in order to improve the accuracy of prenatal diagnosis, thus allowing these cases to be managed at dedicated centers, with consequent reduction of maternal mortality and morbidity. According to a meta-analysis from D'Antonio et al which included 23 studies and 3707 pregnancies at risk for PAS, the performance of ultrasound in diagnosing PAS disorders is excellent, with a sensitivity of $91 \%$ and a specificity of $97 \% .{ }^{29} \mathrm{~A}$ more recent meta-analysis from Jauniaux et al, which included pregnancies presenting with placenta previa or low-lying placenta and one or more prior cesarean deliveries, identified 328 $(8.4 \%)$ cases of placenta previa accreta out of which 298 $(90.9 \%)$ were diagnosed prenatally by ultrasound. ${ }^{30}$ In this study, all cases were diagnosed by ultrasound either during the second or the third trimester. MRI has been increasingly used for prenatal diagnosis of PAS disorders. A metaanalysis found that prenatal MRI is highly accurate, with $94 \%$ sensitivity and $84 \%$ specificity, and concluded that ultrasound and MRI have comparable predictive accuracy, although MRI was superior at predicting the depth and topography of placental invasion. ${ }^{31}$ The importance of a thorough evaluation by an ultrasound expert in all cases with placenta previa and previous cesarean scar to rule out PAS disorders must be emphasized.

Recent FIGO and American College of Obstetrics and Gynecology (ACOG) guidelines state that ultrasonography should be the first line investigation for the diagnosis of PAS disorders, while MRI, not being essential for prenatal diagnosis, may be useful in evaluating the pelvic extension of a placenta percreta or areas difficult to evaluate on ultrasound. ${ }^{16,32}$ Women at greatest risk for placenta accreta are those who have myometrial damage caused by an earlier cesarean delivery with placenta previa overlying the uterine scar, and this risk rises with the number of previous cesarean deliveries. ${ }^{33}$ In this cohort, all women had at least one 
previous cesarean delivery and all of them presented with placenta previa overlying a previous cesarean section scar. Other risk factors for PAS include procedures with potential damage to the integrity of the uterine lining, such as uterine curettage, endometrial ablation, hysteroscopic surgery, myomectomy, manual delivery of the placenta and uterine artery embolization. ${ }^{15,34}$

In our study, median gestational age at delivery was 36 weeks. Although there is insufficient evidence to determine the exact optimal age for planned delivery, FIGO guidelines suggest that women who are stable with no antepartum hemorrhage, rupture of membranes or uterine contractions may be considered for planned delivery at $36-37$ weeks, after administration of corticosteroids for lung maturity. ${ }^{19,35,36}$

The main limitation of this study consists of the small number of cases. Another limitation is the fact that, during this ten-year period, protocols regarding management of PAS necessarily changed in order to catch up with new scientific evidence. Despite these limitations, is important to highlight that, although the total number of analyzed cases is small, they were all treated in the same center by a dedicated team, following institutional protocols throughout the study period. Moreover, and as far as we know, this is one of the first Portuguese series concerning cases of PAS overlying a previous CS scar.

\section{CONCLUSION}

The increased incidence of PAS is a direct consequence of the increased number of cesarean deliveries worldwide. This condition is associated with high levels of maternal and neonatal morbidity and mortality. A history of prior caesarean delivery and the presence of placenta previa should alert the obstetrics team to the highest risk of PAS. Early antenatal diagnosis of this condition is critical for a multidisciplinary planning that may reduce potential morbidity and mortality and ensure better maternal and fetal outcomes. A scheduled and controlled approach, performed at dedicated centers (centers of excellence), significantly reduces maternal morbidity and mortality. This series of 15 cases reports the reality of a tertiary perinatal care center in Portugal, in which no maternal or neonatal mortality due to PAS was registered over the last decade. This is attributed to efficient prenatal diagnosis and a coordinated and multidisciplinary team approach.

\section{PROTECTION OF HUMANS AND ANIMALS}

The authors declare that the procedures were followed according to the regulations established by the Clinical Research and Ethics Committee and to the Helsinki Declaration of the World Medical Association, updated in 2013.

\section{DATA CONFIDENTIALITY}

The authors declare having followed the protocols in use at their working center regarding patients' data publication.

\section{COMPETING INTERESTS}

The authors have declared that no competing interests exist.

\section{FUNDING SOURCES}

This research received no specific grant from any funding agency in the public, commercial, or not-for-profit sectors.

Gynecol Clin North Am. 2013;40:137-54.

10. Solheim K, Esako T, Li le S, Cheng Y, Sparks T, Caughey A. The effect of cesarean delivery rates on the future incidence of placenta previa, placenta accreta, and maternal mortality. J Matern Fetal Neonatal Med. 2011;24:1341-6.

11. Silver R, Landon M, Rouse D, Leveno K, Spong C, Thom E, et al. Maternal morbidity associated with multiple repeat cesarean deliveries. Obstet Gynecol. 2006;107:1226-32.

12. Shellhaas C, Gilbert S, Landon M, Varner M, Leveno K, HauthJ, et al. The frequency and complication rates of hysterectomy accompanying cesarean delivery. Obstet Gynecol. 2009;114: 224-9.

13. Blanchette $\mathrm{H}$. The rising cesarean delivery rate in America: what are the consequences? Obstet Gynecol. 2011;118:687-90.

14. Hess JR. Massive blood transfusion. 2018. [accessed 2019 Jul 28]. Available from: https://www.uptodate.com/contents/massive-bloodtransfusion.

15. Silver R, Fox K, Barton J, Abuhamad A, Simhan H, Huls C, et al. Center of excellence for placenta accreta. Am J Obstet Gynecol. 2015;212:5618.

16. Jauniaux E, Bhide A, Kennedy A, Woodward P, Hubinont C, Collins $\mathrm{S}$; for the FIGO Placenta Accreta Diagnosis and Management Expert Consensus Panel. FIGO consensus guidelines on placenta accreta spectrum disorders: prenatal diagnosis and screening. Int J Gynecol Obstet. 2018;140:274-80.

17. Shamshirsaz A, Fox K, Salmanian B, Diaz-Arrastia C, Lee W, Baker $B$, et al. Maternal morbidity in patients with morbidly adherent placenta treated with and without a standardized multidisciplinary approach. Am J Obstet Gynecol. 2015;212:218.e1-9. 
18. Smulian J, Pascual A, Hesham H, Qureshey E, Thomas M, Depuy A, et al. Invasive placental disease: the impact of a multidisciplinary team approach to management. J Matern Fetal Neonatal Med. 2017;30:14237.

19. Allen L, Jauniaux E, Hobson S, Papillon-Smith J, Belfort M; for the FIGO Placenta Accreta Diagnosis and Management Expert Consensus Panel. FIGO consensus guidelines on placenta accreta spectrum disorders: nonconservative surgical management. Int J Gynecol Obstet. 2018;140:281-90.

20. Pinto P, Guimarães S, Machado A, Montenegro N. Placenta accreta clinical experience of a tertiary care center over 8 years. Acta Obstet Ginecol Port. 2019;13:148-54.

21. Parra-Herran C, Djordjevic B. Histopathology of placenta creta: chorionic villi intrusion into myometrial vascular spaces and extravillous trophoblast proliferation are frequent and specific findings with implications on diagnosis and pathogenesis. Int $\mathrm{J}$ Gynecol Pathol. 2016;35:497-508.

22. Grace Tan S, Jobling T, Wallace E, McNeilage L, Manolitsas T, Hodges R. Surgical management of placenta accreta: a 10-year experience. Acta Obstet Gynecol Scand. 2013;92:445-50.

23. Cal M, Ayres-de-Campos D, Jauniaux E. International survey of practices used in the diagnosis and management of placenta accreta spectrum disorders. Int J Gynaecol Obstet. 2018;140:307-11.

24. Esakoff T, Handler S, Granados J, Caughey A. PAMUS: placenta accreta management across the United States. J Matern Fetal Neonatal Med. 2012;25:761-5.

25. Sentilhes L, Kayem G, Chandraharan E, Palacios-Jaraquemada J, Jauniaux E; for the FIGO Placenta Accreta Diagnosis and Management Expert Consensus Panel. FIGO consensus guidelines on placenta accreta spectrum disorders: conservative management. Int J Gynecol Obstet. 2018;140:291-8.

26. Sentilhes L, Kayem G, Ambroselli C, Provansal M, Fernandez H Perrotin $F$, et al. Fertility and pregnancy outcomes following conservative treatment for placenta accreta. Hum Reprod. 2010;25:2803-10.
27. Salim R, Chulski A, Romano S, Garmi G, Rudin M, Shalev E. Precesarean prophylatic balloon catheters for suspected placenta accreta: a randomized controlled trial. Obstet Gynecol. 2015;126:10228.

28. Thurn L, Lindqvist $P$, Jakobsson $M$, Colmorn L, Klungsoyr K, Bjarnadóttir $\mathrm{R}$, et al. Abnormally invasive placenta - prevalence, risk factors and antenatal suspicion: results from a large population-based pregnancy cohort study in the Nordic countries. BJOG. 2016;123:1348-55.

29. D'Antonio F, lacovella $C$, Bhide A. Prenatal identification of invasive placentation using ultrasound: systematic review and meta-analysis. Ultrasound Obstet Gynecol. 2013;42:509-17.

30. Jauniaux E, Bhide A. Prenatal ultrasound diagnosis and outcome of placenta previa accreta after cesarean delivery: a systematic review and meta-analysis. Am J Obstet Gynecol. 2017;217:27-36.

31. D'Antonio F, lacovella C, Palacios-Jaraquemada J, Bruno C, Manzoli L, Bhide A. Prenatal identification of invasive placentation using magnetic resonance imaging: systematic review and meta-analysis. Ultrasound Obstet Gynecol. 2014;44:8-16.

32. Committee on Obstetric Practice. Committee opinion no. 529: placenta accreta. Obstet Gynecol. 2012;120:207-11.

33. Silver R, Landon M, Rouse D, Leveno K, Spong C, Thom E, et al. Maternal morbidity associated with multiple repeat cesarean deliveries. National Institute of Child Health and Human Development MaternalFetal Medicine Units Network. Obstet Gynecol. 2006;107:1226-32.

34. Pron G, Mocarski E, Bennett J, Vilos G, Common A, Vanderburgh L. Pregnancy after uterine artery embolization for leiomyomata: the Ontario Multicenter Trial. Ontario UFE Collaborative Group. Obstet Gynecol. 2005;105:67-76.

35. Bowman Z, Manuck T, Eller A, Simon M, Silver RM. Risk factors for unscheduled delivery in patients with placenta accreta. Am J Obstet Gynecol. 2014;210:241.e1-6.

36. Rac M, Wells C, Twickler D, Moschos E, Mclntire D, Dashe J. Placenta accreta and vaginal bleeding according to gestational age at delivery. Obstet Gynecol. 2015;125:808-13. 